\title{
Profil volume oksigen maksimal pemain sepak bola Unibraw 82 Malang
}

\section{Maximum oxygen volume profile of Unibraw 82 Malang soccer players}

\section{Budijanto*1, Rubbi Kurniawan $^{1}$, Ratno Susanto'}

${ }^{1}$ Program Studi Pendidikan Jasmani, Kesehatan, dan Rekreasi, IKIP Budi Utomo, Malang, Indonesia

${ }^{*}$ Corresponding Author

\begin{abstract}
Abstrak
Tujuan penelitian ini adalah untuk mengetahui tingkat volume oksigen maksimal $\left(\mathrm{VO}_{2} \mathrm{max}\right)$ pada pemain sepak bola Unibraw 82 Malang. Penelitian menggunakan jenis penelitian deskriptif kuantitatif dengan Teknik survei. Sampel penelitian adalah pemain sepak bola Unibraw 82 Malang yang berjumlah 21 orang. Instrumen yang digunakan adalah berupa Multistage Fitness Test. Hasil penelitian yang diperoleh bahwa nilai $\mathrm{VO}_{2}$ max terendah yang dimiliki pemain sepak bola Unibraw 82 Malang adalah sebesar $27,6 \mathrm{ml} / \mathrm{kg} / \mathrm{min}$, sedangkan nilai $\mathrm{VO}_{2} \max$ tertinggi adalah sebesar $54,1 \mathrm{ml} / \mathrm{kg} / \mathrm{min}$. Nilai rata-rata $\mathrm{VO}_{2}$ max pemain sepak bola Unibraw 82 Malang adalah sebesar 39,2 dengan variasi data sebesar 55,6 dan simpangan baku sebesar 7,5. Berdasarkan hasil penelitian yang telah dilakukan, dapat disimpulkan bahwa tingkat $\mathrm{VO}_{2}$ max pemain sepak bola Unibraw Malang sebanyak $10 \%$ pemain masuk dalam kategori baik, $14 \%$ pemain masuk dalam kategori cukup, 29\% pemain masuk dalam kategori rendah dan $48 \%$ pemain masuk dalam kategori sangat rendah.
\end{abstract}

Kata Kunci: Volume Oksigen Maksimal; Atlet; Sepak Bola; Profil.

\begin{abstract}
The purpose of this study was to find out the maximum oxygen volume level $\left(\mathrm{VO}_{2} \max \right)$ in Unibraw 82 Malang soccer players. Research uses a type of quantitative descriptive research with survey techniques. The study sample was 21person Unibraw 82 Malang soccer players. The instrument used is a Multistage Fitness Test. The results of the study obtained that the lowest $\mathrm{VO}_{2}$ max value owned by Unibraw 82 Malang soccer players was $27.6 \mathrm{ml} / \mathrm{kg} / \mathrm{min}$, while the highest $\mathrm{VO}_{2} \max$ value was $54.1 \mathrm{ml} / \mathrm{kg} / \mathrm{min}$. The average $\mathrm{VO}_{2} \max$ value of Unibraw 82 Malang soccer players is 39.2 with a data variation of 55.6 and a raw deviation of 7.5. Based on the results of research that has been done, it can be concluded that the $\mathrm{VO}_{2}$ max level of Unibraw Malang soccer players as many as $10 \%$ of players fall into a good category, $14 \%$ of players fall into a sufficient category, $29 \%$ of players fall into a low category and $48 \%$ of players fall into a very low category.
\end{abstract}

Keywords: Maximal Oxygen Volume; Athlete; Soccer; Profile.

Received: 6 Februari 2022; Revised: 8 Februari 2022; Accepted: 12 Februari 2022

Corresponding author: Budijanto, Jln. Simpang Arjuno No. 14, Malang, 65119, Jawa Timur

Email: budijanto@budiutomomalang.ac.id 


\section{PENDAHULUAN}

Permainan sepak bola adalah olahraga permainan bola besar nan sangat populer di Indonesia. Magnet permainan sepak bola terletak pada kealamian permainannya is a (Adziman et al., 2017). Permainan sepak bola adalah cabang olahraga beregu yang dimainkan oleh 11 orang setiap regu (Fahrial, 2016). Permainan ini akan berjalan dengan baik apabila setiap pemain telah menguasai teknik dasar permainan sepak bola.

Selain teknik dasar yang harus dikuasai, pemain sepak bola juga dituntut memiliki tingkat kebugaran jasmani yang tinggi. Salah satu indikator tingkat kebugaran yang tinggi adalah seorang pemain sepak bola harus memiliki tingkat kapasitas oksigen maksimal $\left(\mathrm{VO}_{2} \mathrm{max}\right)$ yang tinggi, merupakan banyaknya oksigen maksimal yang dapat dikonsumsi oleh tubuh dalam satuan $\mathrm{ml} / \mathrm{kg} / \mathrm{min}$ (Samodra \& Mashud, 2021). Volume Oksigen Maksimal $\left(\mathrm{VO}_{2} \max \right)$ merupakan materi daya tahan yang dihasilkan oleh kemampuan jantung beserta paru-paru dalam menghirup oksigen dan menyalurkannya ke bagian tubuh yang bekerja dalam rentang waktu lebih dari tiga menit (Budiwanto, 2012).

Volume Oksigen Maksimal ( $\left.\mathrm{VO}_{2} \max \right)$ dapat diukur dengan menggunakan Multistage Fitness Test (MFT). Bentuk tes ini memiliki jumlah kelebihan, yaitu data $\mathrm{VO}_{2}$ max lebih akurat dibandingkan dengan tes lapangan lainnya, dan dapat dilaksanakan secara masal serta tidak membutuhkan lokasi nan luas cukup dengan tersedianya lapangan dengan panjang sekitar 20 meter. Maka dari itu eksplorasi ini akan menggunakan tes lari Multistage Fitness Test (MFT) untuk mengetahui tingkat Volume Oksigen Maksimal $\left(\mathrm{VO}_{2} \max \right) \cdot \mathrm{VO}_{2} \max$ adalah ukuran nan sangat penting, karena tidak cukup untuk mengetahui bahwa atlet memiliki kapasitas konsumsi oksigen nan besar tetapi penting juga untuk disadari seberapa banyak oksigen nan dikonsumsi (Jorgić et al., 2011; Nuarti et al., 2019). Kapasitas aerobik merupakan elemen penting untuk menunjang kesuksesan dalam prestasi olahraga (Hendrawan \& Raya, 2021). Efisiensi cardiovascular mencerminkan kapasitas individu untuk melakukan upaya fisik maksimal untuk jangka waktu nan relatif lama serta untuk mengukur 
efisiensi cardiovascular (Mishra et al., 2015). $\mathrm{VO}_{2} \max$ merupakan faktor penentu dalam menentukan tingkat kebugaran cardiovascular dan $\mathrm{VO}_{2}$ max digunakan untuk mengukur kapasitas oksigen maksimal yang digunakan selama aktivitas fisik nan tinggi (Bhat \& Shaw, 2017).

Berdasarkan beberapa pendapat ahli yang dijelaskan di atas, disimpulkan bahwa $\mathrm{VO}_{2}$ max merupakan komponen penting untuk pemain sepak bola. Selain digunakan sebagai acuan kemampuan fisik pemain sepak bola, $\mathrm{VO}_{2} \max$ juga digunakan sebagai indikator kapasitas aerobik dan fungsi kardiorespirasi serta penentu penting kesuksesan dalam prestasi olahraga.

\section{METODE}

Penelitian ini menggunakan jenis eksplorasi yang bersifat deskriptif kuantitatif dengan teknik survei. Penelitian deskriptif adalah eksplorasi yang direncanakan jelang menganalisis keadaan, kondisi atau hal lain-lain nan alhasil untuk dalam bentuk laporan eksplorasi (Maksum, 2018). Eksplorasi ini dilakukan untuk mendeskripsikan peristiwa yang terjadi pada saat ini. Deskripsi peristiwa tersebut dilakukan secara sistematis yang menekankan pada pengungkapan data berdasarkan fakta yang diperoleh dari lapangan (Winarno, 2014). Tujuan penelitian ini adalah untuk menganalisis tingkat Volume Oksigen Maksimal $\left(\mathrm{VO}_{2} \max \right)$ pada Eksponen sepak bola Unibraw 82 Malang.

Populasi dalam eksplorasi ialah Eksponen sepak bola Unibraw 82 Malang. Pengutipan sampel saat eksplorasi mencadangkan teknik pemilihan sampel yaitu semua pemain yang berjumlah 21 orang. Instrumen eksplorasi dalam eksplorasi ialah tes. Tes merupakan serentetan pertanyaan atau edukasi atau alat lain nan Diaplikasikan jelang mengukur keterampilan, pengetahuan intelegensi, kemampuan atau bakat nan dimiliki individu atau kelompok (Arikunto, 2013). Tes yang digunakan adalah Multistage fitness test (MFT) untuk mengukur tingkat volume oksigen maksimal $\left(\mathrm{VO}_{2} \max \right)$ (Bayu et al., 2021; Paradisis et al., 2014). 


\section{HASIL}

Berdasarkan penelitian yang telah dilakukan, diperoleh tingkat volume oksigen maksimal $\left(\mathrm{VO}_{2} \max \right)$ pada Eksponen sepak bola Unibraw 82 Malang nan diperoleh dari tes multistage fitness test. Data nan telah diperoleh dianalisis menggunakan tabel prediksi $\mathrm{VO}_{2 \max }$ lalu dilanjutkan dengan kategorisasi $\mathrm{VO}_{2} \max$. Hasil dari tes lari multistage fitness test, prediksi $\mathrm{VO}_{2} \max$ dan kategori prediksi $\mathrm{VO}_{2} \max$ dijabarkan pada tabel berikut ini.

Tabel 1. Nilai $\mathrm{VO}_{2}$ max berdasarkan tes Multistage Fitness Test

\begin{tabular}{clc}
\hline No & Komponen & Nilai \\
\hline 1 & Nilai terendah & 27,6 \\
2 & Nilai tertinggi & 54,1 \\
3 & Rata-rata & 39,2 \\
4 & Varian & 55,6 \\
5 & Simp. Baku & 7,5 \\
\hline
\end{tabular}

Berdasarkan tabel 1 di atas diperoleh data bahwa nilai $\mathrm{VO}_{2} \max$ terendah yang dimiliki oleh pemain sepak bola Unibraw 82 Malang adalah sebesar $27,6 \mathrm{ml} / \mathrm{kg} / \mathrm{min}$, sedangkan nilai $\mathrm{VO}_{2} \max$ tertinggi adalah sebesar $54,1 \mathrm{ml} / \mathrm{kg} / \mathrm{min}$. Nilai rata-rata $\mathrm{VO}_{2} \max$ pemain sepak bola Unibraw 82 Malang adalah sebesar 39,2 dengan variasi data sebesar 55,6 dan simpangan baku sebesar 7,5.

Tabel 2. Kategorisasi $\mathrm{VO}_{2}$ max pemain sepak bola Unibraw 82 Malang

\begin{tabular}{clcc}
\hline No & Kategori & Jumlah & Prosentase \\
\hline 1 & Sangat Baik & 0 & $0 \%$ \\
2 & Baik & 2 & $10 \%$ \\
3 & Cukup & 3 & $14 \%$ \\
4 & Rendah & 6 & $29 \%$ \\
5 & Sangat Rendah & 10 & $48 \%$ \\
\hline Jumlah & 21 & $100 \%$ \\
\hline
\end{tabular}

Berdasarkan tabel 2 diketahui bahwa jumlah pemain sepak bola Unibraw 82 Malang nan mendapat $\mathrm{VO}_{2}$ max kategori baik sebanyak 2 orang (10\%), $\mathrm{VO}_{2} \max$ kategori cukup sebanyak 14 orang (14\%), $\mathrm{VO}_{2}$ max kategori rendah sebanyak 6 orang (29\%), dan $\mathrm{VO}_{2} \max$ kategori sangat rendah sebanyak 10 orang (48\%). Kategori sangat baik memiliki persentase 0\%, artinya bahwa $\mathrm{VO}_{2} \max$ yang dimiliki masing-masing pemain sepak bola Unibraw 82 tidak ada yang masuk dalam kategori sangat baik. Nilai rata- 
rata $\mathrm{VO}_{2} \max$ dimiliki oleh pemain sepak bola Unibraw 82 Malang adalah $39,2 \mathrm{ml} / \mathrm{kg} / \mathrm{min}$ masuk dalam kategori rendah, nilai $\mathrm{VO}_{2} \max$ tertinggi adalah sebesar $54,1 \mathrm{ml} / \mathrm{kg} / \mathrm{min}$ masuk dalam kategori baik dan nilai $\mathrm{VO}_{2 \max }$ terendah adalah sebesar $27,6 \mathrm{ml} / \mathrm{kg} / \mathrm{min}$ masuk dalam kategori sangat rendah.

\section{PEMBAHASAN}

Volume Oksigen Maksimal ( $\left.\mathrm{VO}_{2} \max \right)$ ialah kapabilitas tubuh jelang mengonsumsi oksigen secara optimal dalam ukuran selang waktu tertentu, biasanya dalam satuan menit (Sudiana, 2017). Orang nan kebugarannya baik mempunyai nilai $\mathrm{VO}_{2} \max$ yang lebih tinggi dan dapat melakukan aktivitas lebih kuat dari pada mereka nan tidak dalam kondisi baik (Watulingas et al., 2013).

VO2max penting untuk diketahui, karena digunakan untuk menguji dan mengetahui seberapa besar asupan Oksigen selama aktivitas fisik (Nunes et al., 2018). VO2max merupakan indikator efektivitas sebuah program latihan (Boss et al., 2010; Pratama et al., 2019). VO2max merupakan alat ukur kapasitas aerobik dan fungsi kardiorespirasi yang digunakan untuk memprediksi respons tubuh selama melakukan aktivitas fisik dalam waktu yang lama (Kaka \& Magied, 2014; Warren et al., 2017).

Dalam eksplorasi ini diketahui bahwa rata-rata tingkat VO2max Eksponen sepak bola Unibraw 82 adalah sebesar $39,2 \mathrm{ml} / \mathrm{kg} / \mathrm{min}$ nan masuk dalam kategori rendah, dengan 29\% Eksponen masuk dalam kategori rendah dan 48\% Eksponen masuk dalam kategori sangat rendah . Hal ini tentunya merupakan hasil yang kurang memuaskan, karena sepak bola adalah olahraga yang membutuhkan tingkat kebugaran jasmani nan sangat tinggi, tidak terkecuali $\mathrm{VO}_{2} \max$ (Boone et al., 2012).

Sebagai solusi untuk meningkatkan VO2max Eksponen sepak bola Unibraw 82 Malang adalah dengan membuat program latihan nan sistematis, teratur dan progresif (Budi \& Sugiharto, 2015). Bentuk latihan nan bisa digunakan diantaranya adalah latihan aerobik dan latihan anaerobik. Kedua latihan tersebut memiliki pengaruh yang sama terhadap 
peningkatan volume oksigen maksimal $\left(\mathrm{VO}_{2} \max \right)$ pemain sepak bola (Budijanto \& Kurniawan, 2020).

\section{KESIMPULAN}

Berdasarkan hasil eksplorasi yang telah dilakukan, dapat disimpulkan bahwa tingkat VO2max pemain sepak bola Unibraw Malang sebanyak 10\% Eksponen masuk dalam kategori baik, 14\% pemainmasuk dalam kategori cukup, 29\% pemain masuk dalam kategori rendah dan $48 \%$ pemain masuk dalam kategori sangat rendah.

\section{KONTRIBUSI PENULIS}

Penulis 1: Writing - Review \& Editing - Original Draft; Penulis 2: Methodology; Penulis 3: Software and Writing - Validating.

\section{DAFTAR PUSTAKA}

Adziman, L., Arwin, A., \& Syafrial, S. (2017). Profil Kondisi Fisik Pemain Sepak Bola Sma Negeri 1 Kaur. Kinestetik, 1(1). https://doi.org/10.33369/jk.v1i1.3373

Arikunto, S. (2013). Prosedur Penelitian: Suatu Pendekatan Praktik. Rineka Cipta.

http:/ / r2kn.litbang.kemkes.go.id:8080/handle/123456789/62880

Bayu, W. I., Waluyo, W., Victorian, A. R., Ikhsan, A. I. A1, \& Apriyanto, Y. (2021). Instrumen Tes Kebugaran Jasmani Untuk Anak Usia 10-12 Tahun. Sporta Saintika, 6(2), 165-176. https:/ / doi.org/ 10.24036/SPORTA.V6I2.186

Bhat, S. A., \& Shaw, D. (2017). Development of norms of maximal oxygen uptake (VO2 max.) as an indicator of aerobic fitness of high altitude male youth of Kashmir. International Journal of Physiology, Nutrition and Physical Education, 2(2), 1037-1040.

Boone, J., Vaeyens, R., Steyaert, A., Bossche, L. Vanden, \& Bourgois, J. (2012). Physical Fitness of Elite Belgian Soccer Players by Player Position. Journal of Strength and Conditioning Research, 26(8), 20512057. https://doi.org/10.1519/JSC.0b013e318239f84f

Boss, A., Lecoultre, V., Ruffieux, C., Tappy, L., \& Schneiter, P. (2010). Combined effects of endurance training and dietary unsaturated fatty acids on physical performance, fat oxidation and insulin sensitivity. British Journal of Nutrition, 103(8), 1151-1159. https://doi.org/10.1017/S000711450999287X

Budi, M. F. S., \& Sugiharto. (2015). Circuit Training Dengan Rasio 1:1 dan Rasio 1:2 Terhadap Peningkatam VO2max. JSSF, 4(3).

Budijanto, B., \& Kurniawan, R. (2020). Aerobic Vs. Anaerobic Training to 
Increase VO2max Soccer Players. International Journal of Multicultural and Multireligious Understanding, 7(9), 383-387. https://doi.org/10.18415/IJMMU.V7I9.2130

Budiwanto, S. (2012). Metode Latihan Olahraga. Universitase Negeri Malang.

Fahrial, A. (2016). Sepak Bola. Universitas Negeri Malang.

Hendrawan, S., \& Raya, G. A. S. (2021). Analisis Kapasitas Aerobik Maksimal Mahasiswa Pendidikan Jasmani Dan Rekreasi Pada Masa Pandemi Covid19. Jurnal Kejaora (Kesehatan Jasmani Dan Olah Raga), 6(2), 301-305. https://doi.org/10.36526/kejaora.v6i2.1568

Jorgić, B., Puletić, M., Okičić, T., \& Meškovska, N. (2011). Importance of Maximal Oxygen Consumption During Swimming. Facta Universitatis: Physical Education and Sport, 9(2), 183-191.

Kaka, K. H., \& Magied, A. (2014). Effect of Concurrent Training on VO2max, Certain Physical Variables and Spike Performance for Young Female Volleyball Players. Ovidius University Annals, Series Physical Education and Sport Science, Movement and Health, XIV(2), 437-441.

Maksum, A. (2018). Metodologi Penelitian dalam Olahraga. Unesa University Press.

Mishra, M. K., Pandey, A. K., \& Chaubey, D. (2015). A Comparative Study of Vo2 Max among the Basketball, Football, Volleyball and Hockey Male Players. International Journal of Applied Research, 1(11), 245-247.

Nuarti, N., Huldani, \& Asnawati. (2019). Perbandingan Kapasitas Oksigen Maksimal Antara Laki-Laki dan Perempuan pada Calon Jemaah Haji. Homeostasis, 2(1), 125-130.

Nunes, R., Silva, J., Machado, A., Menezes, L., Bocalini, D., Seixas, I., Lima, V., \& Vale, R. (2018). Prediction of Vo2 max in healthy non-athlete men based on ventilatory threshold. Retos, 35, 136-139. https:/ / doi.org/10.47197/RETOS.VOI35.62165

Paradisis, G. P., Zacharogiannis, E., Mandila, D., Smirtiotou, A., Argeitaki, P., \& Cooke, C. B. (2014). Multi-Stage 20-m Shuttle Run Fitness Test, Maximal Oxygen Uptake and Velocity at Maximal Oxygen Uptake. Journal of Human Kinetics, 41(1), 81-87. https://doi.org/10.2478/hukin-2014-0035

Pratama, R. R., Bayu, W. I., Reza Resah Pratama, \& Wahyu Indra Bayu. (2019). Pengaruh Metode Sircuit Terhadap Daya Tahan Aerobik Pada Siswa Di Sma Negeri 9 Ogan Komering Ulu. Jurnal Kejaora (Kesehatan Jasmani Dan Olahraga), 4(2), 14-17. https://doi.org/10.36526/kejaora.v4i2.706

Samodra, Y. T. J., \& Mashud, M. (2021). Analisis kemampuan VO2max cabang olahraga beladiri. Altius: Jurnal Ilmu Olahraga Dan Kesehatan, 10(1), 78-88. https://doi.org/10.36706/altius.v10i1.13759

Warren, B. G., Spaniol, F., \& Bonnette, R. (2017). The Effects of an Elevation Training Mask on VO2max of Male Reserve Officers Training Corps Cadets. International Journal of Exercise Science, 10(1), 37-43. 
Watulingas, I., Rampengan, J. J. V, \& Polii, H. (2013). Pengaruh Latihan Fisik Aerobik Terhadap VO2max pada Mahasiswa Pria Dengan Berat Badan Lebih (Overweight). Jurnal E-Biomedik (EBM), 1(2), 1064-1068.

Winarno, M. E. (2014). Evaluasi Dalam Pendidikan Jasmani dan Olahraga. Center for Human Capacity Development. 